geological structure of the region is included, also an analysis of those earth movements which have affected the area. Each geological epoch represented is treated individually, and bibliographies of the literature are provided. A short chapter deals with the igneous rocks of the area, and another concerns itself with the economic deposits. Two appendixes provide records of recent important bore-holes, and also a list of Geological Survey photographs of the area.

\section{The Art of Interviewing}

The British Association for Commercial and Industrial Education has produced a pamphlet which should find readers well outside the range of those for whom it was intended. Written by John S. Gough, of I.C.I., Ltd., the pamphlet Interviewing in Twenty-six Steps describes the approach to an interview designed to select a candidate for a job, the method of conducting it, the dangers and diversions to be avoided and the way the interview should be used in summing-up the candidate. The pamphlet is forthright, practical and has clearly been written by one who has tried out his twenty-six steps on many occasions before summarizing them in this form. Gough makes it clear that no skilled interviewer can guarantee success in selection; the more he practises, the less mistakes he should make. This pamphlet will help him to reduce his number of failures. Copies may be obtained from the British Association for Commercial and Industrial Education, 26a Buckingham Palace Road, London, S.W.1; price $3 s .6 d$.

\section{Applications of Solar Energy}

IN Solar Energy Technology : 1954-1959 (Library Association. Special Subject List No. 34. Pp. 32. London: Library Association, 1961. 3s. 6d.), T. Brimelow attempts to list all the significant literature on the subject published in Europe and the United States with the exception of items published in the popular and political periodicals of the U.S.S.R. The 329 items are arranged in sections which include: aero/space applications; air-conditioning; automotive engineering; biological science; electrical conversion; furnaces; heating; radio; refrigeration; water heating and water treatment. There are an author index and also a subject index, and a brief introduction by Dr. H. Heywood notes the salient features in present applications of solar energy.

\section{Scientific Research in British Universities, 1960-61}

Scientific Research in British Universities, 1960-61, issued by the Department of Scientific and Industrial Research, is an indispensable handbook for all those who endeavour to keep track of scientists in the United Kingdom and their fields of research (Pp. xiii +513 . London: H.M.S.O., 1961. 32s. 6d. net). The handbook describes the nature of research projects in progress, and indicates the scope of research carried out by various scientific departments and individual teams of investigators. Entries are made in alphabetical order of university, and subdivided into faculty and subject. Simple numerical headings of universities and subject allow ease of reference. Three indexes are provided, satisfying any search by name, subject heading or actual research.
Lady Tata Memorial Trust: Awards for 1961-62

THE Trustees of the Lady Tata Memorial Trust, on the recommendation of the (European) Scientific Advisory Committee, have made the following awards for research on leukæmia and allied diseases in the academic year beginning October 1: Grants for research expenses, Dr. J. L. Amiel, Cancer and Radiopathology Research Centre, Paris; Dr. B. M. Braganca, Indian Cancer Research Centre, Bombay; Dr. G. W. Griffith, County Health Department, Anglesey; Dr. B. Lagerlof, Karolinska Institute, Stockholm; Dr. H. J. Woodliff, New Pathology Laboratory, Radcliffe Infirmary, Oxford. Scholarship, Dr. L. Chieco-Bianchi, Institute of Pathological Anatomy, Bari.

\section{Awards in Radiological Research and Nuclear Medicine: James Picker Foundation}

ON behalf of the James Picker Foundation, the National Academy of Sciences-National Research Council is accepting applications for fellowships and grants in the field of radiology and nuclear medicine for the year 1962-63. Awards are made in four categories: (1) Advanced Fellowships in Academic Radiology. Completion of clinical training in radiology ordinarily will be a prerequisite, and the candidate must be prepared to devote a minimum of two years to course work in the basic sciences and to the application of the techniques and methods of these basic disciplines to radiological research. (2) Postdoctoral Research Fellowships, open to recent graduates who desire investigative experience and training in radiology or nuclear medicine. Applicants must hold the M.D., Ph.D. or Sc.D. degree or the equivalent. Awards are for a period of one year. (3) Grants for Scholars, to assist medical schools in supporting and developing junior staff members in radiology. Initial grants are made for two years. (4) Grants-in-Aid of Research are designed to encourage investigations in radiology and nuclear medicine offering promise of improvement in methods of diagnosis or treatment of disease. These grants may be made for two years. Applications for the fiscal year 1962-63 should be submitted by October 1, 1961, to the Committee on Radiology, National Academy of Sciences-National Research Council, 2101 Constitution Avenue, N.W., Washington 25, D.C.

\section{The Institute of Physics and the Physical Society}

AT the first annual general meeting of the amalgamated Institute of Physics and the Physical Society, held in London on July 4, the following were elected to office: President, Sir John Cockeroft; Vice-Presidents, Dr. V. E. Cosslett, Prof. R. W. Ditchburn, Dr. W. H. Taylor and Dr. J. Topping; Honorary Treasurer, Dr. J. Taylor; Honorary Secretary, Dr. C. G. Wynne. Eight ordinary members of Council were also elected. This, the first elected Council of the amalgamated body, is very nearly the same as the 'caretaker' Council which has been in office since the amalgamation of the Institute and Society on July 5, 1960.

\section{University News:}

Leeds

THe Foundation for Management Education has arranged for grants totalling $£ 16,600$ a year for seven years to be made available to the University of Leeds. This will make possible the strengthening of the present teaching in management studies for students 